\title{
The Contribution of Music and Movement Activities to Creative Thinking in Pre-School Children
}

\author{
Elena Chronopoulou ${ }^{1}$, Vassiliki Riga ${ }^{2}$ \\ ${ }^{1}$ Hellenic Open University, Patras, Greece \\ ${ }^{2}$ Department of Educational Sciences \& Early Childhood Education, University of Patras, Patras, Greece \\ Email: vriga@upatras.gr
}

Received February $23^{\text {rd }}, 2012$; revised March 27 $7^{\text {th }}, 2012$; accepted April $2^{\text {nd }}, 2012$

\begin{abstract}
As interest in creativity is rising, kindergarten teachers are looking for ways to strengthen the creative potential of young children. The aim of this study was to investigate the effect of music and movement activities to creative thinking in preschool children. A three month educational programme was designed and implemented, using an experimental research method. The effect on fluency, flexibility, originality and elaboration of thought of 5-year-old children, as well as how the programme affected creative behaviours, was studied. The results, upon completion of the educational programme, showed that the growth rate of these variables in the experimental group was statistically significant compared to the corresponding rates in the control group. In addition, the emergence of creative behaviours, such as an increased freedom of expression, a tendency to explore and experiment, and a questioning of what is commonly accepted, were considered to be a consequence of the implementation of the specific educational programme. The experimental research produced valuable information about the design and philosophy of educational programmes, and about the teaching methods of music and movement activities in kindergarten.
\end{abstract}

Keywords: Creative Thinking; Movement; Music; Preschool Children; Play

\section{Introduction}

Studies (Bidri, 2005; Hosseini \& Watt, 2010; Sternberg, 2003) have been conducted in order to investigate how creativity can be taught and nurtured through education. Many researchers (Howard-Jones et al., 2002; Russ et al., 1999; Tarnowski, 1999) have emphasized the link between play and creative thinking in preschool education. Janjolo and Stamp (in Morin, 2001: p. 25) also noted the similarities between play and music, indicating that both have a symbolic and rule-governed nature, and are meaningful and active. Furthermore, other researchers (Littleton, 1991; Niland, 2009; Smithrim, 1997 in Morin, 2001) have indicated the educational value of music play in children's creative thinking.

Considering all the above, this study attempted to answer the following research questions:

1) Can a programme of educational interventions, which is based on music and movement activities, help the development of creative thinking in preschool children?

2) Which behaviours or creative abilities have improved the most as a result of these educational interventions?

3) How could the curriculum in kindergartens be reformed in order to create the conditions that promote the development of children's creative thinking and creative behaviours?

\section{Purpose}

Considering that the encouragement of creative thinking may be possible in a creative learning environment, the objective of this research was to examine the relation between the creative thinking of preschoolers and music and movement activities in order to determine whether, and to what extent, these kind of activities help to develop creativity.
Early childhood researchers acknowledged the importance of play not only in promoting children's development (Singer \& Singer, 1990; Slade \& Wolf 1994), but also in fostering children's creativity (Balke, 1997; Russ et al., 1999). More specifically, applying the play theory to musical education, Professor Swanwick (1988) suggested that there is a correlation between major play aspects and musical activities. Karl Orff and Emil Dalcroze focused on the connection between music and rhythm and movement, using musical play and kinaesthetic play in their training programmes (Niland, 2009). In our study the following techniques were used: movement, singing, the use of percussion instruments, active listening, creative expression, music reading and writing.

A comprehensive programme of educational interventions for preschoolers was designed to explore the hypothesis that music and movement activities enhance the characteristics of creative thinking, such as fluency, flexibility, originality, and elaboration, as well as certain creative behaviours in children. These behaviours were selected by reviewing relevant studies (Polland, 1994; Segal, 2001; Torrance, 1965), concerning the characteristics of creative individuals. The behaviours referred to: dedication to a goal, tendency for exploration and experimentation-curiosity, confidence, imagination, challenging the commonly accepted (i.e. non-conventionality), and freedom to express ideas, thoughts and feelings.

\section{Method}

In order to examine the research questions a quasi-experimental design was adopted. At first a programme of sixteen educational interventions was designed, based on music and movement activities. Next, two groups of kindergarten children 
were selected, the experimental group and the control group. The experimental group attended the assistance programme for three months, while the control group did not participate in it. To maintain internal validity, the control group shared common features with the experimental group (age, socio-economic background and geographic region). In addition, double evaluation was applied in both groups according to Campbell and Stanley's principals (1963) (before and after the experiment), and the results were compared with each other in order to extract the conclusions of the research.

\section{Participants}

The experiment was conducted in a public kindergarten. There were two classes operating in the kindergarten and one of them was randomly determined to be the experimental group. The two groups were similar in terms of age and number, as well as in the percentage between the two sexes. More specifically, the control group was composed of 18 children (13 boys and 5 girls), while the experimental was composed of 15 children ( 11 boys and 4 girls). The children in both groups were 5 years old. It should be noted that the two classes were housed in the same building, therefore the stimulus by the curriculum, such as educational programmes, tours, celebrations, etc., and the everyday conditions and habits, such as school facilities and play areas during intervals, were basically the same. At the same time, the fact that all children lived in the same area allowed us to assume that differences due to socio-cultural factors between the two groups were minor.

\section{Procedure}

The experiment began in January and was completed in May. During the first weeks, all the pre-tests were conducted in order to assess the level of creativity in both groups. In the following weeks, a total of sixteen educational interventions took place twice a week over a three month period. Each intervention was 45 - 60 minutes long. Upon completion of the programme, both groups were evaluated with the post-tests. The tests used in the second measurement were the same in concept, structure and nature of activities as the pre-tests, but differed in their content.

\section{Development of Data Collection Methods}

Due to the complex and multidimensional nature of creativity, the assessment cannot be considered reliable and efficient if it is based only on one measurement instrument (Treffinger et al., 2002). Thus, it was decided to use different and complementary research tools (the creativity tests, the observation plans, and the interviews) in order to triangulate the results and explain them in a holistic manner.

\section{Creativity Tests}

Torrance's Tests of Creative Thinking (TTCT) do not measure creativity but rather estimate and diagnose the possibility of producing creative thinking, not in a specific sector but in a wider context (Torrance, 1966c). TTCT tests are the most common standardized and balanced tests in which creative thinking is characterized by the fluency, flexibility, originality and elaboration of ideas (Guilford, 1975: pp. 37-43). The tests have been in use over a period of 25 years, and have been applied to different people in terms of age, socio-cultural back- ground and gender, which according to the researchers has confirmed the internal validity of the variables, the scoring method of the responses, and the assessment of the results (Kerr $\&$ Gagliardi, 2003; Kyung-Hee, 2006). TTCT tests are applicable at preschool age, have been adapted for the assessment of creative thinking in music, and have been applied in Vaughan's and Myers' (1971) and Webster's $(1983,1987)$ tests (in Kiehn, 2003).

We used the two types of Torrance tests, TTCT-Figural and TTCT-Verbal. Each of them has two parallel forms A and B, which involve similar activities. In the current study form A was used for the pre-test and form B was used for the post-test. The figural tests consist of three activities: Picture construction, picture completion, and repeated figures of lines or circles. The activities of the verbal tests refer to: ask and guess, product improvement, unusual uses, unusual questions, and just suppose.

The variables used for rating the performance of children in the tests were the four characteristics of creative thinking (fluency, flexibility, originality, and elaboration). The method of scoring the variables was based on proposals by Torrance (1966a, 1966b, 1974a, 1974b) and the performance results were recorded on individual student record sheets.

\section{Observation Plan}

The dynamic nature of the development of creative thinking and the hypothesis that a creative person is an evolving entity, highlight the need for information to be collected over time rather than at particular moments. For this reason, participative observation of the children by the researcher was chosen as a second research tool during the educational interventions in order to answer the first two research questions. An observation plan was structured that referred to both the characteristics of creative thinking and the creative behaviours. A weighted rating scale was used to assess the creative behaviours (Treffinger et al., 2002: pp. 59-62). The four subdivisions (non- evident yet, emerging, expressing, excelling) reflect the level of studied behaviour, indicating the degree of its acquisition or its maturity. The plan played a "retroactive" role, since the researcher's additional comments were used as a means of partial evaluation of the educational interventions and they provided information for possible improvements.

\section{Individual Interviews}

Interviews were used, at the beginning and at the end of the interventions, as a primary tool for collecting the opinions of the kindergarten teachers concerning each child's creativity. We also looked at how teachers perceive creativity, the creative process, the supporting factors and the restraining factors on the expression of creative thought. The interviews were semistructured and consisted of open and closed questions, which were simple and specific (Oppenheim, 1992: p. 155) to ensure a high degree of reliability and accuracy of results, and to minimize the expression of personal opinion of the teachers.

Since the aim was to produce results that could be compared with those obtained through the observations, the variables selected (creative behaviours) as well as the measurement scale used in both cases were the same. In this way the responses of kindergarten teachers were able to be collected in the form of quantitative data and to be analyzed further through comparison 
with the corresponding quantitative observation data.

\section{Development of Educational Programme}

The design of the educational interventions was based on principles used in other educational programmes that have been developed to promote creativity (Santanen et al., 1999; Xanthakou, 1998; Xanthakou \& Kaila, 2002). To be effective, the teaching interventions took place in an environment that encouraged freedom of expression and provided opportunities for development of personal initiative and psychological safety (Leonidou, 2005: p. 55). In addition, recommendations, bias, premature criticism and evaluation of children's ideas, were prevented (Xanthakou, 1998). Amabile (1982) highlighted that in educational interventions one should seek to activate inner motivation as well as grant sufficient time to children to express all their ideas. Harrington (1990) summarised all the conditions that encourage and stimulate creative ideas under the term of "Creative Ecosystem".

The structure of the educational interventions were divided in four thematic areas:

$1^{\text {st }}$ area: Sound (tone colour, silence, pitch, dynamics, execution mode);

$2^{\text {nd }}$ area: Rhythm (rhythmic values, rhythmic sense of closure, identification, composition, improvisation and performance of different rhythmic patterns);

$3^{\text {rd }}$ area: Melody (upward and downward movement of the melody, structure and form of a melody);

$4^{\text {th }}$ area: Combination (melody quality characteristics, rhythmic and melodic variations, aesthetic approach to the rhythm, sound and melodic patterns-energy);

And moved in three axes:

1) The activation of knowledge skills (musical concepts);

2) The activation of emotional skills through identifying and expressing personal ideas, feelings and mood, and;

3) The discouragement of typical ways of thinking.

More specifically, in the first axis, certain activities were used to enhance the process of problem solving, the spontaneous production of many ideas, the free association, the analyticcal and synthetic ability, the recall of prior knowledge, data processing, and the concentration to achieve a goal. In the second axis, the expression of emotional skills and attitudes was fostered through role-playing, improvisation, imitation, debate, and generally through the emotional behaviour in the classroom. The third axis, which is inherent in the two previous ones, provided activities that were based on avoiding conventional thinking and stimulating the expression of spontaneous and emotional moods that are unusual.

Each intervention began either with introductory activities during which indirect references to the topic of intervention were made or with a short repetition of some previous experience. The last ten minutes of the activities were devoted to choreographies or movement improvisations, to relaxation and also to discussions. Although the programme followed some specific strategies, its structure and application were carried out under a flexible framework that allowed dynamic adjustment in accordance with the children's ideas and initiatives.

\section{Results}

\section{Results of Schematic Tests}

Following Torrance's schematic test manuals (1966a, 1974a), the results of the pre-test showed that elaboration was the variable with the highest average in both the experimental group (EG) and the control group (CG), and flexibility was the variable with the lowest minimum value. Generally, both groups showed a similarity regarding the variables in question, which was found with the use of t-test for independent samples. The pre-test did not reveal statistically significant differences when comparing the mean value of originality $(t=-1.266)$, elaboration $(\mathrm{t}=-1.717)$, fluency $(\mathrm{t}=-1.974)$ and flexibility $(\mathrm{t}=-0.959)$ between the two groups. In particular, since $p>0.05$, the null hypothesis that the two groups demonstrated almost equal level of creative thinking was confirmed (see Table 1 ).

The Table 2 shows the results of the post-test for both groups upon the completion of interventions. According to Table 2, the performance of the students in the experimental group improved compared to those in the control group, as well as to their own performance before the interventions. Specifically, the t-test showed a statistically significant difference in the mean value of fluency $(\mathrm{t}=-2.28 ; p<0.05)$, flexibility $(\mathrm{t}=$ $-7.33 ; p<0.05)$, originality $(\mathrm{t}=-6.041 ; p<0.05)$ and elaboration $(\mathrm{t}=-3.145 ; p<0.05)$ in the experimental group before and after the interventions. Thus, the alternative hypothesis that the mean value of these variables is different (and bigger) after the interventions was confirmed. On the contrary, there was no statistically significant difference in the values of fluency $(\mathrm{t}=$ $-1.808 ; p>0.05)$, flexibility $(\mathrm{t}=-1.991 ; p>0.05)$ and elaboration $(\mathrm{t}=-1.495 ; p>0.05)$ in the control group, except from the value of originality $(\mathrm{t}=-5.992 ; p<0.05)$, a result that leads to the assumption that the interventions could lead to the improvement of originality but are not deemed essential.

At the end of the experiment, statistically significant differences were found in the mean values of fluency $(t=-2.763)$, flexibility $(\mathrm{t}=-3380)$, originality $(\mathrm{t}=-2.247)$ and elaboration $(t=-2.134)$. Therefore, the interventions contributed to the diversification of initially same levels of variables between the two groups.

The relationship between the four characteristics of creative thinking was examined using the Pearson correlation coefficient, $\mathrm{t}$ (see Table 3).

Overall, the correlation coefficients between changes in the variables were not statistically significant $(p>0.05)$. For example, an increase in elaboration was not associated with an increase in originality, fluency and flexibility. The only statistically significant correlation coefficient was that between fluency and flexibility in the control group. Specifically, an increase in fluency was accompanied by an increase in flexibility in the control group.

\section{Results of Verbal Tests}

The assessment manuals of Torrance verbal tests (1966b, 1974b) provide a balanced way for assessing children's responses regarding the four variables. The statistical function t-test for paired samples was used to investigate whether there is a statistically significant difference in these variables. The results showed a statistically significant difference in the mean value of fluency in the experimental group $(\mathrm{t}=-3.704 ; p<0.05)$ at the end of the interventions. Thus, the successive intervenetions improved the performance of fluency.

Also, the statistical results of the experimental group revealed improved flexibility regarding the alternative uses and possible interpretations of objects, and situations and ideas for 
Table 1.

Results of pre-test for both groups.

\begin{tabular}{|c|c|c|c|c|c|c|c|c|}
\hline & \multicolumn{2}{|c|}{ Originality } & \multicolumn{2}{|c|}{ Elaboration } & \multicolumn{2}{|c|}{ Fluency } & \multicolumn{2}{|c|}{ Flexibility } \\
\hline & EG & $\mathrm{CG}$ & EG & $\mathrm{CG}$ & EG & $\mathrm{CG}$ & EG & CG \\
\hline Mean value & 16.43 & 13.57 & 28.71 & 24.42 & 20.50 & 17.28 & 13.92 & 12.28 \\
\hline Standard deviation & 5.07 & 6.74 & 6.59 & 6.61 & 2.03 & 5.74 & 2.75 & 5.78 \\
\hline Coefficient of variation & 0.31 & 0.50 & 0.23 & 0.27 & 0.10 & 0.33 & 0.20 & 0.47 \\
\hline Mode & 12 & 20 & 25 & 26 & 22 & 22 & 15 & 19 \\
\hline Minimum value & 11 & 3 & 19 & 10 & 15 & 9 & 8 & 3 \\
\hline Maximum value & 29 & 29 & 46 & 32 & 22 & 28 & 17 & 20 \\
\hline
\end{tabular}

Table 2.

Results of post-test for both groups.

\begin{tabular}{|c|c|c|c|c|c|c|c|c|}
\hline & \multicolumn{2}{|c|}{ Originality } & \multicolumn{2}{|c|}{ Elaboration } & \multicolumn{2}{|c|}{ Fluency } & \multicolumn{2}{|c|}{ Flexibility } \\
\hline & EG & CG & EG & $\mathrm{CG}$ & EG & CG & EG & $\mathrm{CG}$ \\
\hline Mean value & 23.14 & 18 & 32.57 & 26.35 & 21.35 & 19.42 & 17.42 & 13.85 \\
\hline Standard deviation & 5.8 & 6.30 & 7.12 & 8.24 & .84 & 2.47 & 1.86 & 3.48 \\
\hline Coefficient of variation & 0.25 & 0.35 & 0.22 & 0.31 & 0.04 & 0.13 & 0.11 & 0.25 \\
\hline Mode & 20 & 20 & 29 & 20 & 22 & 22 & 18 & 18 \\
\hline Minimum value & 15 & 10 & 24 & 8 & 20 & 15 & 14 & 8 \\
\hline Maximum value & 36 & 32 & 50 & 38 & 22 & 22 & 20 & 19 \\
\hline
\end{tabular}

Table 3.

Correlations of changes in variables of two groups.

\begin{tabular}{|c|c|c|c|c|c|c|c|c|c|}
\hline & & \multicolumn{2}{|c|}{ Originality } & \multicolumn{2}{|c|}{ Elaboration } & \multicolumn{2}{|c|}{ Fluency } & \multicolumn{2}{|c|}{ Flexibility } \\
\hline & & EG & $\mathrm{CG}$ & EG & CG & EG & $\mathrm{CG}$ & EG & $\mathrm{CG}$ \\
\hline \multirow{2}{*}{ Originality } & Pearson correlation coefficient & & & -0.41 & 0.16 & 0.18 & 0.20 & -0.03 & 0.09 \\
\hline & p-value & & & 0.15 & 0.58 & 0.55 & 0.49 & 0.92 & 0.75 \\
\hline \multirow{2}{*}{ Elaboration } & Pearson correlation coefficient & -0.41 & 0.16 & & & 0.29 & 0.20 & 0.32 & -0.15 \\
\hline & p-value & 0.15 & 0.58 & & & 0.31 & 0.50 & 0.27 & 0.60 \\
\hline \multirow{2}{*}{ Fluency } & Pearson correlation coefficient & 0.18 & 0.20 & 0.29 & 0.20 & & & 0.43 & 0.90 \\
\hline & p-value & 0.55 & 0.49 & 0.31 & 0.50 & & & 0.13 & 0 \\
\hline \multirow{2}{*}{ Flexibility } & Pearson correlation coefficient & -0.03 & 0.09 & 0.32 & -0.15 & 0.43 & 0.90 & & \\
\hline & p-value & 0.92 & 0.75 & 0.27 & 0.60 & 0.13 & 0 & & \\
\hline
\end{tabular}

dealing with hypothetical/imaginary situations. However, there was no improvement in flexibility concerning the assumption of causes and the assumption of effects/results.

Significant differences between pre-test and post-test was found also in originality $(\mathrm{t}=-5.8 ; p<0.05)$ and elaboration $(\mathrm{t}=$ $-9.32 ; p<0.05)$ in the experimental group. However, the respective measurements in the control group indicated no statistically significant difference between the pre-test and post-test results.

\section{Results of the Observation Plan}

The data recorded by the researcher showed that, although the percentage change of fluency for each level (not yet evident, emerging, expressing and excelling) is not linear, the overall change indicates a very significant increase in fluency in the experimental group. During the interventions the percentage of students $(67 \%)$ not showing fluency characteristics (not yet evident) decreased dramatically (7\%). At the same time, during the first intervention the percentage of students with the maximum level of fluency (excellent) was only $8 \%$, while during the last intervention the percentage increased to $58 \%$.

The horizontal axis of Figure 1 shows the educational interventions, while the vertical shows the percentage of students in the experimental group related to fluency.

Figures 2-4 show the percentage change of the other charac- 


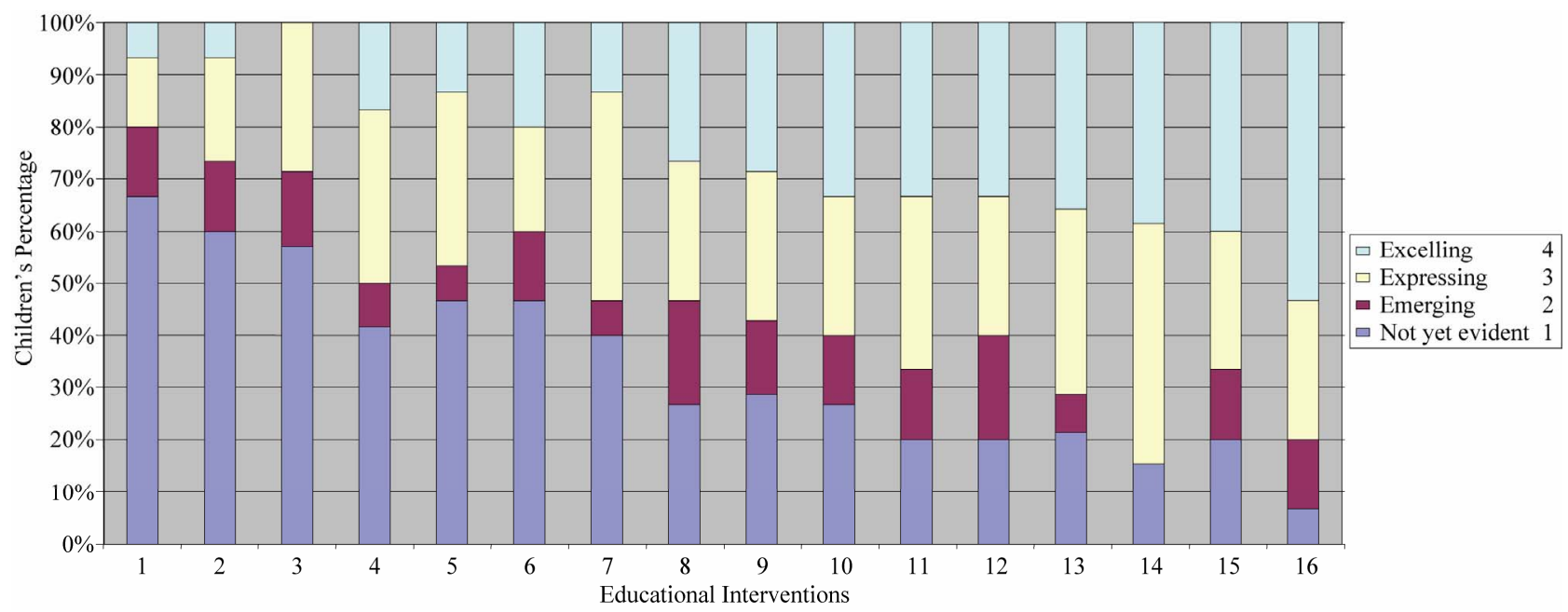

Figure 1.

The percentage change of fluency in each level for each educational intervention.

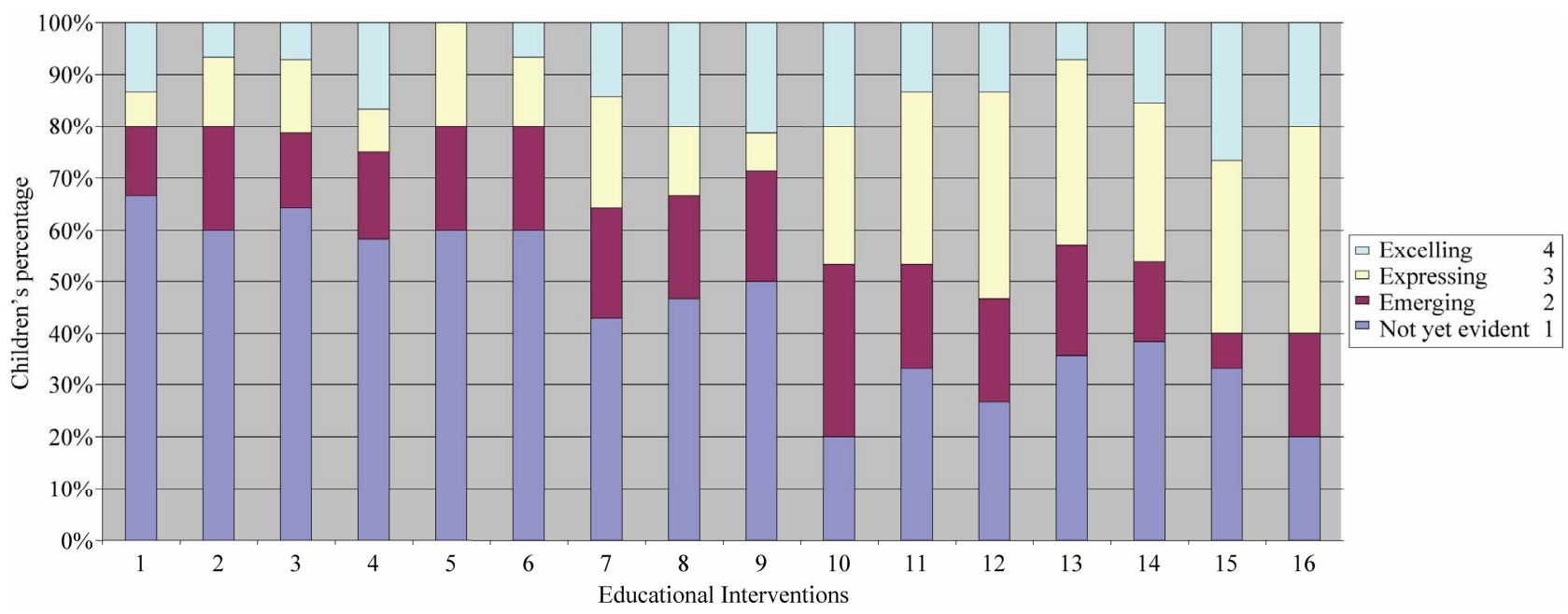

Figure 2.

The percentage change of flexibility in each level for each educational intervention.

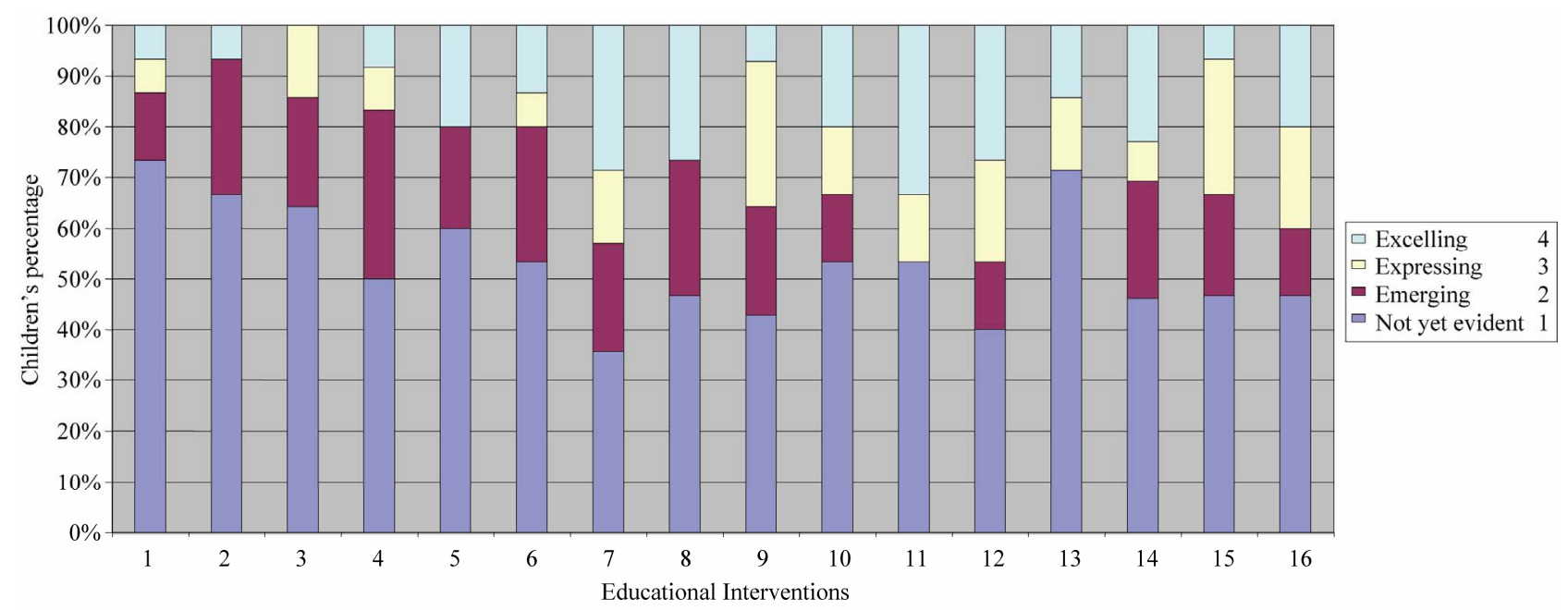

Figure 3.

The percentage change of originality in each level for each educational intervention. 


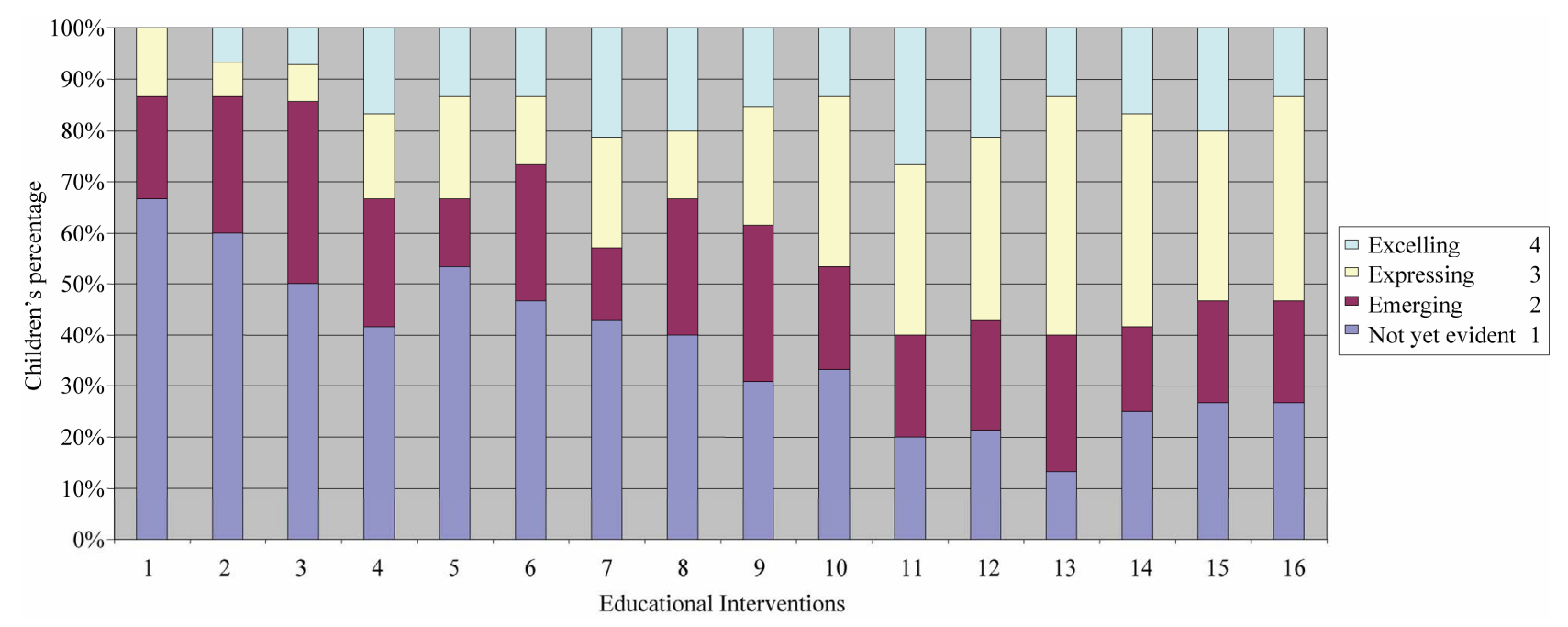

Figure 4.

The percentage change of elaboration in each level for each educational intervention.

teristics of creative thinking (flexibility, originality and elaboration) for each level and each intervention. It should be noted that flexibility increased at a lower rate than fluency. It should also be noted the dramatic increase in the percentage of students whose flexibility was assessed is apparent (see Figure 1).

Figure 3 shows that in all, originality is increased, giving different rates of students without linear continuity for each level/stage and intervention.

Figure 4 shows the percentage change in terms of elaboration. Generally, there is an increase in the percentage of students in higher levels, more evident in the third one, in which the elaboration is apparent.

Similar figures were also produced for the following three creative behaviours:

- Freedom of expression,

- Tendency to explore and experiment,

- Challenging the commonly accepted.

These behaviours were ranked by the kindergarten teachers as the most important creative behaviours. During the interventions a significant increase, from $8 \%$ to $68 \%$, was observed by the researcher in freedom of expression. Moreover, the percentage of children whose freedom of expression was characterized as not evident yet, decreased from $72 \%$ to $28 \%$. Children's willingness to participate in experimentation and exploration activities increased during the interventions, and the percentage of the "not yet evident" level reached zero. Finally, there was a significant percentage change, from $8 \%$ to $40 \%$, in the "emerging" level of the third behaviour.

\section{Results from the Interviews with Kindergarten Teachers}

Table 4 shows the kindergarten teachers' responses for the two groups after the educational interventions. It is clear that the experimental group got better results than the control group. The behaviours in which the experimental group showed superiority are: freedom of expression, self confidence, and fantasy (see Table 4).

The assessment of the open questions leads to the conclusion that the characteristics that are rewarded and reinforced during creative teaching depend on both the teachers' personality and the lack of training in the field of creativity. Thus, there is a need for training kindergarten teachers to assess creative thinking and behaviours in different ways. Hosseini and Watt (2010) provided evidence that teachers' training programmes aimed to improve the understanding of creativity-oriented techniques, contribute positively to the development of students' creativity.

It is also worth noting that teachers view the children's tendency not to act according to the norm as a threat to the educational process and not as a sign of initiative and creativity.

\section{Discussion}

\section{Conclusions on the Characteristics of Creative Thinking}

The pre- and post-test results prove the positive impact of the interventions. The control group, though starting from the same level of creativity as the experimental group, with the exception of originality, did not show a statistically significant increase in any of the characteristics of creative thinking.

Concerning fluency, the results of both Torrance's tests and those of the observation plan indicate that fluency level increased at the end of the experiment. The rate of the increase varied according to the research measurement tool. More specifically, the analysis of the schematic tests indicated a limited increase in fluency. This may be due to the predetermined number of drawings children are asked to design during the test (the structure of pre- and post-tests is limited to ten drawings and does not allow the recording of more ideas). This interprettation is verified by the children's respective performances in the verbal test, where there is no predetermined number of responses. Moreover, the increase in fluency is more evident in the analysis of the observation plan. Children seem to be more willing and find it easier to produce more ideas during the educational interventions than during the test. This is likely to be due to the supporting role of the group, the conditions of teaching and the educational techniques (for example, the brainstorming technique). Therefore, the change in fluency seems to vary depending on the research tool used for assessment. This was also identified in Han, Marvin and Walden's (2003) study, 
Table 4.

Results of the interviews before and after the intervations.

\begin{tabular}{|c|c|c|c|c|c|c|c|c|}
\hline & \multicolumn{2}{|c|}{ Not yet evident } & \multicolumn{2}{|c|}{ Emerging } & \multicolumn{2}{|c|}{ Expressing } & \multicolumn{2}{|c|}{ Excelling } \\
\hline & EG & CG & EG & CG & EG & CG & EG & CG \\
\hline Freedom of expression (post-test) & & & & & * & & & $* *$ \\
\hline (pre-test) & * & $* *$ & & & & & & \\
\hline Tendency for exploration and experimentation (post-test) & & & * & $* *$ & & & & \\
\hline (pre-test) & * & $* *$ & & & & & & \\
\hline Commitment to a goal (post-test) & & & & & $*$ & $* *$ & & \\
\hline (pre-test) & & $* *$ & * & & & & & \\
\hline Challenging the commonly accepted (post-test) & * & & & $* *$ & & & & \\
\hline (pre-test) & * & $* *$ & & & & & & \\
\hline Self confidence (post-test) & & & * & & & $* *$ & & \\
\hline (pre-test) & * & $* *$ & & & & & & \\
\hline Fantasy (post-test) & & & * & & & $* *$ & & \\
\hline (pre-test) & & & * & $* *$ & & & & \\
\hline
\end{tabular}

where low correlation between TTCT test and NSNO (Nebraska Starry Night Observation) tool was found on the assessment of fluency.

Concerning flexibility, the results of the schematic tests indicate the positive impact of educational interventions. The same conclusion can be reached based on the results of the verbal tests, where an increase in flexibility occurred due to the use of appropriate teaching techniques. The correlation between the creativity variables was examined further as the individual analysis of each variable could lead to misleading or superficial conclusions. Torrance (1966c) underlined the need to examine the correlation between the variables. He noted that an increase in fluency does not always lead to creativity, since it could result from spontaneous thoughts or responses of children, and therefore it has to be associated with the other variables. The opposite results are extracted by the observation plan where there is an increase in both variables, with a notable increase in fluency. These different findings are due to the fact that children express their creativity better during the educational process, and that fluency is more easily identifiable and measurable in a context of participatory observation than flexibility.

Concerning originality, a statistically significant increase was detected in both groups. Therefore, our research assumption that the educational interventions would increase originality is not initially verified. However, the fact that the originality/ fluency ratio in the control group varied significantly, while the corresponding ratio in the experimental group remained stable, indicates that the real originality was increased in the experimental group. In addition, the results of the observation plan show an overall development of originality in the experimental group. We also observed that the degree and the form of expression of originality does not increase in a linear way, but is strongly influenced by exogenous factors (probably the type of interventions or the teacher's mood) and endogenous factors (such as the children's mood).

In terms of elaboration, the test results showed a statistically significant increase in the experimental group but not in the control group. Students in the experimental group managed to produce and complete ideas faster than before, and to stay focused on a goal. Yet, there were students whose performance in elaboration reduced, while their fluency increased. This was demonstrated as a difficulty in staying concentrated and focussed on a goal, as increased willingness to try anything different, as low willingness to participate in this test or by trying to complete their drawings as quickly and simply as possible. However, the simultaneous increase in fluency and elaboration is not a sufficient indicator of creative thought; it has to be accompanied by a corresponding increase in the other variables as well. According to the researcher's additional records during the participative observation, students who had difficulty in producing original ideas insisted on perfecting their own idea by using many complementary elements in order to make their drawing special, and thus increasing in this way their performance in elaboration.

Increased creativity is not evident in the same way in all people. As observed, other children express it easier verbally and others schematically. In this context, Rose and Lin (1984: pp. 5-50) referred to the dual nature of creativity as a conesquence of the different ways it is expressed. Therefore, unilateral interpretation of the relationships between the characteristics of creative thinking does not give us the possibility of generalized interpretations unless the specific characteristics of each student are considered.

\section{Conclusions on the Creative Behaviours}

The existence of creative behaviours does not necessarily guarantee the existence of creativity, but it is an indication of potential creative thinking. According to the results of participative observation, there was an increase in the children's freedom of expression during the interventions. A significant increase was found in the highest level (excelling), suggesting the effortless, self-sustained child's need for expression. This was also verified by the kindergarten teachers' interviews at the end of the interventions. Freedom of expression seems to be 
reinforced through activities of movement improvisation, free movement and discussions in a circle. Overall, the reinforcement of group dynamics, communication, and emotional interaction with classmates, creates an atmosphere of joy and confidence which enhances spontaneous and free expression. In addition, several students who were initially reluctant to take up roles in the group (such as being the leaders or conductors) or to present their work (one of their drawings) to their classmates, managed to overcome their hesitation, and began to seek roles and generally opportunities to express themselves.

The tendency of students to explore and experiment was also increased during the interventions. During the last three interventions, there was no student in the experimental group whose will for experimentation and exploration was classified as not apparent. This is a result of the use of exploration activities during the educational interventions. This behaviour, if analyzed in depth, may imply an increase in other behaviours such as: students' tolerance to unfamiliar situations, their willingness to take risks, and their curiosity.

The questioning of what is commonly accepted shows less pronounced changes in percentage levels compared to previous behaviours. According to the results of the interviews, the predisposition of the students in the experimental group to challenge the commonly accepted from "not yet evident" became "emerging", while the students' predisposition in the control group remained "not yet evident". The limited or even the absence of questioning the commonly accepted that was noted, could be explained by what Piaget called stage of morel realism (in Woodhead et al., 1999: p. 199). Children of 4 years or above consider rules to be inviolable and their violation punishable. Also, the research data reflect the cultural structure of western society, which rewards obedience and condemns any questioning of societal structures.

The selection of three research tools helped to increase the range and possibly the complexity of the research. The survey's reliability was increased due to the way the results were analyzed, i.e. through the variables' correlations. More specifically, it was observed that if the results were to be analyzed separately for each variable and their correlations, they could have given different, complementary, overlapping, or even contradictory conclusions.

Moreover, it should be noted that the independent (educational interventions) and dependent variables (creative behaviours) are not incompatible and independent from each other, but they increase while feeding one another. This interdependence affects the conclusions. The original hypothesis concerned the influence of music and movement activities in children's creative thinking; the research verified part of this hypothesis and in particular highlighted the positive impact of games targeting creativity.

To conclude with, the research provides sufficient evidence that specific models of educational interventions can lead to the further development of children's creativity. However, there are several limitations which have to be considered. The sample size was relatively small to proceed on generalizations to other kindergarten children. Additionally, such educational programmes are not on their own sufficient for the development of creativity. The teacher's interest and dedication to the promotion of creativity, the use of creative teaching techniques, the creation of an environment which promote children's creativity are also required. Therefore, the design of relevant in-service teachers training programmes could be a key factor to enhance chil- dren's creativity. In our study we didn't take into account the children's social interactions during the implementation of the educational innervations neither the affective interaction between researcher and children. We didn't also discuss the impact of the characteristics of the educational system and the official curriculum in children's creativity. Finally, further implementation is needed on a more extended sample and in different socio-cultural preschool settings to give more precise answers to our research questions.

\section{Implications for Practice}

The basic proposal of this research involved the identification of strategies and principles that are considered complementary to the development of creativity. In the design of music and movement activities, playing is proposed as a suitable tool for developing children's creativity, based on the following techniques:

- The use of brainstorming;

- The use of imaginary/hypothetical stories;

- The alternative use of objects;

- The alternative approach to situations;

- Experimenting and searching;

- Dealing with problematic situations;

- Predicting causes and effects of a situation;

- And is structured according to the following principles:

- Encourages the expression of emotion;

- Promotes the child's unique view;

- Strengthens the child's initiative;

- Encourages the formulation of unusual ideas and relationships;

- Provides psychological security and freedom of expression.

However, even the best designed educational programme is not sufficient to promoting creative thinking and to fostering creative behaviours. The general philosophy behind the organization and the flow of the educational process which creates the atmosphere in which this process takes place is very important. In this context, Treffinger (1993) suggested that increased creativity results from the discovery and the enhancement of each child's special skills. It is recommended, therefore, that teachers encourage means by which children can discover their own creative skills independently of their kindergarten teacher.

In regards to the implementation of these tests, it is suggested that questions about children's constructions be used to determine more accurately the level of creativity and limit the possibility of misinterpretation. Most importantly, the structure, content and the assessment process should not isolate the socio-cultural factor. A verification process like that can reveal information and effective ways about evaluation, tailored to each situation, or even indicate the need for the overall redefinition of the tests.

Generally, any attempt to study creativity requires taking into account a variety of factors and a critical approach to the use of tests in order to produce scientific results rather than simplistic ones.

\section{REFERENCES}

Amabile, T. M. (1982). The social psychology of creativity: A consensual assessment technique. Journal of Personality and Social Psychology, 43, 997-1013. doi:10.1037/0022-3514.43.5.997

Balke, E. (1997). Play and the arts: The importance of the "unimpor- 
tant". Childhood Education, 73, 353-360.

Birdi, K. S. (2005). No idea? Evaluating the effectiveness of creativity training. Journal of European Industrial Training, 29, 102-111. doi:10.1108/03090590510585073

Campbell, D. T., \& Stanley, J. (1963). Experimental and quasi-experimental designs for research. Chicago, IL: Rand McNally.

Guilford, J. P. (1975). Creativity: A quarter century of progress. In I. A. Taylor, \& J. W. Getzels (Eds.), Perspectives in creativity (pp. 37-59). Chicago: Aldine.

Han, K., Marvin, C., \& Walden, A. (2003). Searching for an alternate way to identify young creative minds: A classroom-based observation approach. Assessment for Effective Intervention, 28, 1-17. doi: $10.1177 / 073724770302800201$

Harrington, D. M. (1990). The ecology of human creativity: A psychological perspective. In M. A. Runco, \& R. S. Albert (Eds.), Theories of creativity (pp. 143-170). London: Sage Publications.

Hosseini, S. A., \& Watt, P. A. (2010). The effect of a teacher professional development in facilitating students' creativity. Educational Research and Reviews, 5, 432-438.

Howard-Jones, P. A., Taylor, J., \& Sutton, L. (2002). The effects of play on the creativity of young children. Early Child Development and Care, 172, 323-328. doi:10.1080/03004430212722

Kerr, B., \& Gagliardi, C. (2003). Measuring creativity in research and practice. In S. J. Lopez, \& C. R. Snyder (Eds.), Positive psychological assessment: A handbook of models and measures. Washington, DC: American Psychological Association. doi:10.1037/10612-010

Kiehn, M. T. (2003). Development of music creativity among elementary school students. Journal of research in Music Education, 51, 278-288. doi: $10.2307 / 3345655$

Kyung-Hee, K. (2006). Critique on the torrance tests of creative thinking. Creativity Research Journal, 18, 3-14. doi: $10.1207 / \mathrm{s} 15326934 \mathrm{crj} 18012$

Leonidou, Ch. (2005). The introduction of creative and critical thinking at school. Study on the course Sociology of Education. Athens: Faculty of Primary Education, National and Kapodistrian University of Athens.

Morin, L. B., (2001). Cultivating music play: The need for changed teaching practice. General Music Today, 14, 24-29.

Niland, A. (2009). The power of musical play: The value of play-based, child-centered curriculum in early childhood music education. General Music Today, 23, 17-21. doi:10.1177/1048371309335625

Oppenheim, A. N. (1992). Questionnaire, design, interviewing and attitude measurement. London: Pinter Pub Ltd.

Polland, M. (1994). The evaluation of creative behaviors. Opinion Papers. Washington, DC: US Department of Education, Educational Resources Information Centre, 1-39.

Rose, L. H., \& Lin, H. T. (1984). A meta-analysis of long-term creativity training programs. Journal of Creative Behavior, 18, 11-22. doi:10.1002/j.2162-6057.1984.tb00985.x

Russ, S. W, Robins, A. L., \& Christiano, B. A. (1999). Pretend play: Longitudinal prediction of creativity and affect in fantasy in children.
Creativity Research Journal, 12, 129-139.

doi:10.1207/s15326934crj1202_5

Santanen, E. L., Briggs, R. O., \& Vreede, G. J. De (1999). A cognitive network model of creativity: A renewed focus on brainstorming methodology. Proceedings of the 20th International Conference on Information Systems, Charlotte, NC.

Segal, M. (2001). Creativity and personality styles: Tools for understanding and inspiring the many voices of creativity. Huntington Beach, CA: Telos Publications.

Singer, D. G., \& Singer, J. L. (1990). The house of make-believe: Children's play and the developing imagination. Cambridge, MA: Harvard University Press.

Slade, A., \& Wolf, D. (1994). Children at play. New York: Oxford University Press.

Smirhrim, K. L. (1997). Free musical play in early childhood. Canadian Journal of Research in Music Education, 4, 17-24.

Sternberg, R. J. (2003). Creative thinking in the classroom. Scandinavian Journal of Educational Research, 47, 325-338. doi: $10.1080 / 00313830308595$

Swanwick, K. (1988). Music, mind and education. New York: Routledge. doi:10.4324/9780203402894

Tarnowski, S. M. (1999). Musical play and young children. Music Educators Journal, 86, 26-29. doi:10.2307/3399573

Torrance, E. P. (1974a). Torrance tests of creative thinking. Directions manual and scoring guide. Figural Test Booklet B. Lexington, MA: Personnel Press.

Torrance, E. P. (1974b). Torrance tests of creative thinking. Directions manual and scoring guide. Verbal Test Booklet B. Lexington, MA: Personnel Press.

Torrance, E. P. (1966a). Torrance tests of creative thinking. Directions manual and scoring guide. Figural Test Booklet A. Lexington: British Library, Personnel Press.

Torrance, E. P. (1966b). Torrance tests of creative thinking. Directions manual and scoring guide. Verbal Test Booklet A. Lexington, British Library: Personnel Press.

Torrance, E. P. (1966c). Torrance tests of creative thinking. Normstechnical manual. Lexington, MA: Personnel Press.

Torrance, E. P. (1965). Rewarding creative behavior: Experiments in classroom creativity. Englewood Cliffs, NJ: Prentice-Hall Inc.

Treffinger, D. J. (1993). Stimulating creativity: Issues and future directions. In S. G. Isaksen, M. C. Murdock, R. L. Firestein, \& D. J. Treffinger (Eds.), Nurturing and developing creativity: The emergence of a discipline (pp. 8-27). Norwood, NJ: Ablex.

Treffinger, D., Young, G., Selby, E., \& Shepardson, C. (2002). Assessing creativity: A guide for educators. Storrs, CT: The National Research Center on the Gifted and Talented.

Woodhead, M., Faulkner, D., \& Littleton, K. (Eds.) (1999). Making sense of social development. Patra: Hellenic Open University.

Xanthakou, C. (1998). Creativity in school. Athens: Ellinika Grammata.

Xanthakou, C., \& Kaila, M. (2002). The creative problem solving. Athens: Atrapos. 